\title{
PERANAN PT. KHARISMA INDAH LESTARI SHIPPING SEBAGAI PERUSAHAAN KEAGENEN DALAM MENANGANI KEDATANGAN KAPAL DI TG. EMAS SEMARANG Aan Rubiyanto ${ }^{1)}$ \\ ${ }^{1)}$ Program Studi Nautika Akademi Pelayaran Niaga Indonesia aan@akpelni.ac.id
}

\section{Abstrak}

Penulisan ini bertujuan untuk menjelaskan peranan keagenan dalam menangani kedatangan kapal yaitu dengan memberikan solusi terhadap masalah-masalah yang terjadi di PT. KHARISMA INDAH LESTARI SHIPPING. Antara lain menyelesaikan clearance in dengan inaportnet serta sandar dengan Integrated Billing System (IBS) pelindo. Meningkatkan koordinasi dengan instansi yang terkait dengan kedatangan kapal. Serta menyiapkan dan mengecek dokumen kapal dalam proses kedatangan kapal agar tidak ada kekurangan dokumen. Metode pengumpulan data dalam penulisan ini dengan metode pengumpulan data yang menghasilkan data diskriptif berupa kata kata tertulis dari orang orang yang melakukan kegiatan di lapangan. Dalam hal ini mengumpulkan data berupa pendekatan terhadap obyek melalui observasi, wawancara dan metode kepustakaan.

Dari hal tersebut dapat disimpulkan bahwa peranan keagenan masih belum di optimalkan maka dari itu di butuhkan evaluasi terhadap beberapa masalah agar terjadi suatu peningkatan dalam pelayanannya serta memfasilitasi yang masih di nilai kurang agar menjadi perusahaan keagenan yang berperan secara baik.

Kata kunci : inaportnet, ibs pelindo, keagenan, peranan,

\section{Abstract}

This writing aims to explain the role of the agency in dealing with ship arrivals, by providing solutions to the problems that occur at PT.KHARISMA LESTARI SHIPPING. For example, 
complete clearance in with Inaportnet and berthing with Integrated Billing System (IBS) Pelindo. Improve coordination with other agencies related to ship arrival. As well as preparing and checking ship documents in the process of arrival of ships so that there is no lack of documents.

Data collection methods in this paper are data collection methods that produce descriptive data in the form of written words from people who carry out activities in the field observed by the author. In this case collecting data in the form of approaches to objects through observation, interviews and literature methods.

From this it can be concluded that the role of the agency is still not optimized so an evaluation of some problems is needed in order to make an increase in its services and facilitate which is still lacking in order to become an agency company that plays a good role.

Keywords: inaportnet, ibs pelindo, agency, role,

\section{A. PENDAHULUAN}

Indonesia merupakan salah satu negara yang mengembangkan sayap dalam dunia perdagangan baik dalam negeri maupun luar negeri. Untuk itu diperlukan sarana transportasi berupa kapal sebagai penghubung antar pulau dan antar negara.

Pelayaran mempunyai peranan yang sangat penting karena hampir sebagian besar kegiatan ekspor dan impor menggunakan jasa perusahaan pelayaran yang mengoperasikan kapal laut. Kapal mempunyai beberapa keuntungan dibanding dengan sarana transportasi lainnya karena memiliki daya angkut yang lebih banyak dengan biaya relatif lebih murah serta resiko yang lebih kecil. Oleh karena itu, kelancaran transportasi laut dengan kapal harus benarbenar dipastikan beroperasi dengan baik dalam artian laik laut. 
Dalam istilah laik laut, faktor sumber daya manusia yang menanganinya tidak dapat diabaikan yaitu berperan sangat penting dalam memastikan kondisi dan kelayakan kapal yang akan berlayar. Untuk profesionalisme dan kedisiplinan dari instansi pemerintah terkait, badan usaha pelabuhan, dan pelaku industri logistik yang sangat dituntut dalam mengontrol kelancaran transportasi laut dengan baik dan sesuai prosedur. Shipping Line / Agent ialah suatu jasa kepelabuhan yang berperan penting dalam kelancaran transportasi laut yang bertanggung jawab atas perijinan dan koordinasi terhadap instansi di pelabuhan sesuai dengan ketentuan yang berlaku.

\section{B. LANDASAN TEORI}

Menurut Levinson (2009) mengatakan peranan mencakup tiga hal yaitu:

1. Peranan meliputi norma-norma yang dihubungkan dengan posisi atau tempat seseorang dalam masyarakat. Peranan dalam arti ini merupakan rangkaian peraturan-peraturan yang membimbing seseorang dalam kehidupan bermasyarakat.

2. Peranan merupakan suatu konsep tentang apa yang dapat dilakukan oleh individu dalam masyarakat sebagai organisasi.

3. Peranan juga dapat dikatakan sebagai perilaku individu yang penting bagi struktur sosial masyarakat.

INAPORTNET adalah portal elektronis yang terbuka dan netral guna memfasilitasi pertukaran data dan informasi layanan kepelabuhan secara cepat, aman, netral dan mudah terintregasi dengan instansi pemerintah terkait, badan usaha pelabuhan dan pelaku industri logistik untuk meningkatkan daya saing komunitas logistik Indonesia. Sistem INAPORTNET berguna untuk melayani proses kedatangan dan keberangkatan kapal dengan cepat dan efisien karena program dilaksanakan secara online. Para pengguna jasa 
kepelabuhanan seluruh Pelindo tak perlu lagi datang ke kantor untuk mengajukan permohonan sandar kapal.

Kini cukup dengan menggunakan aplikasi Integrated Billing System (IBS). IBS, dengan alamat Web: anjungan.pelindo.co.id, para pengguna jasa kepelabuhanan sudah bisa mengajukan permohonan sandar kapal.

"Aplikasi IBS ini merupakan sebuah platform sistem informasi pelayanan jasa pelabuhan berbasis online yang mudah diakses oleh pengguna jasa kepelabuhanan di manapun dan kapanpun. Dalam aplikasi IBS, tidak ditemukan kendala dalam pengoperasiannya dan aplikasi tersebut cukup kompatibel untuk diakses dengan menggunakan segala jenis gadget. Enam pilar yang menjadi unggulan pelayanan berbasis teknologi informasi IBS, yakni E-Regristration, E-Booking, E-Payment, E-Billing, E-Care dan E-Tracking.

Beberapa manfaat dari penerapan sistem IBS antara lain transparansi biaya, efisien penggunaan kertas, kemudahan tracking dalam permohonan serta pelayanan. Selain itu pengguna jasa bisa mengetahui jumlah kapal yang sudah dibongkar setiap harinya.

\section{TUJUAN PENULISAN.}

1. Untuk mengetahui penyebab gangguan server yang terjadi ketika akan menyelesaikan Clearance In menyebabkan penundaan sandar kapal.

2. Untuk mengetahui kurangnya hubungan yang baik antara instansi- instansi yang terkait dalam kelancaran proses pengurusan dokumen kapal.

3. Untuk mengetahui dokumen kapal yang dibutuhkan dalam proses kedatangan kapal di PT. Kharisma Indah Lestari Shipping Tanjung Emas Semarang. 


\section{HASIL PEMBAHASAN}

\section{Gangguan server yang terjadi ketika akan menyelesaikan Clearance In menyebabkan \\ penundaan sandar kapal}

Clearance in dan Clearance out adalah kegiatan utama pada kegiatan operasional perusahaan pelayaran yang bergerak di bidang keagenan. Terutama ketika kedatangan kapal, maka clearance in perlu dilakukan. Di zaman sekarang, proses kedatangan sebuah kapal sudah menggunakan sistem online, yaitu menggunakan INAPORTNET untuk clearance in dan IBS PELINDO untuk proses sandar dan pandu kapal. Kedua sistem ini sangatlah menguntungkan dan mempercepat proses kedatangan sebuah kapal. Dikarenakan sistem online yang digunakan jadi sudah jelas bahwa internet server menjadi kendalanya. Sehingga dengan adanya gangguan server ini proses kedatangan kapal akan menjadi terhambat dan terlambat.

Dikarenakan adanya kendala server yang sampai sekarang belum teratasi dan belum juga selesai, maka penulis mempunyai beberapa solusi atau pemecahan masalah yang mungkin bisa digunakan sebagai panduan untuk memperbaik server dari kedua sistem online ini yaitu :

a. Perlunya perbaikan pada server utama. Dirjen Hubla selaku penanggung jawab terhadap sistem ini bisa bekerja sama dengan pihak tertentu berkaitan dengan perbaikan pada server utama ini.

b. Perlunya perbaikan pada tampilan dan juga sistem kerja di web agar terlihat lebih mudah diakses dan efisien.

c. Perlunya koordinasi dengan pihak terkait, berkaitan dengan kecepatan internet dan kecepatan data transfer, bisa berkoordinasi dengan Kemkominfo dan menyelesaikan masalah agar pelayanan kapal di Indonesia berjalan efektif dan cepat.

d. Selain hal itu, perlu adanya perbaikan internet dan penambahan kecepatan internet dalam perusahaan 
keagenan terutama PT. Kharisma Indah Lestari. Itulah beberapa solusi yang dapat penulis berikan, sehingga bisa digunakan sebagai pedoman untuk kedepannya.

Berkaitan dengan INAPORTNET dan IBS PELINDO, apabila suatu waktu terjadii gangguang server yang cukup lama, maka perusahaan keagenan bisa menggunakan cara manual untuk menyelesaikan proses kedatangan suatu kapal. Adapun kapalkapal yang memang tertera dalam Peraturan Direktur Jenderal Perhubungan Laut Nomor: HK.103/3/II/DJPL-15 tentang Tata Cara Pelayanan Kapal dan Barang Menggunakan INAPORTNET di Pelabuhan (Pasal 2, Ayat (2)) tidak dapat dilayani dengan INAPORTNET sehingga harus digunakan pelayanan secara manual

Dalam INAPORTNET juga sudah dijelaskan mengenai gangguan server sesuai Pasal 17 bahwasanya "Dalam hal terjadi kerusakan/gangguan pada Inaportnet sehingga tidak dapat berfungsi sebagaimana mestinya, penggunaan melalui sistem elektronik untuk sementara waktu diganti dengan cara manual dan Sistem Level Agreement (SLA).

\section{Kurangnya koordinasi dengan instansi-instansi yang terkait dalam kelancaran proses pengurusan dokumen kapal}

Dalam proses kedatangan sebuah kapal di pelabuhan, tentu tidak hanya sistem yang digunakan dalam prosesnya, namun ada koordinasi dengan beberapa instansi yang terkait sehingga proses kedatangan kapal dapat berjalan dengan lancar. Instansi-Instansi ini bertanggung jawab penuh terhadap kedatangan sebuah kapal dan terkoordinir secara baik dengan perusahaan keagenan seperti PT. Kharisma Indah Lestari. Adapun instansi-instansi yang berkaitan dalam kelancaran proses kedatangan kapal :

\section{a. KSOP (Kantor Kesyahbandaran dan Otoritas Pelabuhan)}

Kantor Kesyahbandaran dan Otoritas Pelabuhan mempunyai tugas melaksanakan pengawasan dan penegakan hukum di 
bidang keselamatan dan keamanan pelayaran, koordinasi kegiatan pemerintahan di pelabuhan serta pengaturan, pengendalian dan pengawasan kegiatan kepelabuhanan pada pelabuhan yang diusahakan secara komersial. Dikarenakan di pelabuhan tanjung emas Semarang sudah menggunakan sistem INAPORTNET maka KSOP sebagai pihak yang mengawasi. Dalam kegiatan pelayanan kedatangan kapal yang dilakukan oleh Kantor Kesyahbandaran dan Otoritas Pelabuhan Kelas 1 Tanjung Emas Semarang sebagai instansi yang memberikan ijin dan mengatur mengenai semua aktivitas atau kegiatan di pelabuhan Tanjung Emas Semarang.

\section{b. Kantor Kesehatan Pelabuhan (KKP)}

Kesehatan Pelabuhan (KKP) adalah unit pelaksana teknis di lingkungan kementrian kesehatan yang berada di bawah dan bertanggung jawab kepada Direktur Jenderal Pengendalian Penyakit dan Penyehatan Lingkungan. KKP mempunyai tugas melaksanakan pencegahan masuk dan keluarnya penyakit, penyakit potensial wabah, surveilans epidemiologi, kekarantinaan, pengendalian dampak kesehatan lingkungan, pelayanan kesehatan, pengawasan OMKABA serta pengamanan terhadap penyakit baru dan penyakit yang muncul kembali, bioterorisme, unsur biologi, kimia dan pengamanan radiasi di wilayah kerja bandara, pelabuhan, dan lintas batas darat negara. (Pasal 2 Peraturan Menteri Kesehatan Republik Indonesia Nomor 356/ MENKES/ PER/ IV/ 2008 Tentang Organisasi Dan Tata Kerja Kantor Kesehatan Pelabuhan). Dinas Karantina Kesehatan dalam prakteknya bertugas melayani pengajuan yang dibuat oleh PT. Kharisma Indah Lestari untuk memeriksa kesehatan kapal yang berkaitan dengan penerbitan sanitasi kapal. Sebelum pengajuan SPB di KSOP Kelas 1 Tanjung Emas Semarang, harus sudah ada clearance kesehatan dari kantor karantina kesehatan pelabuhan dengan sebutan Port Health Clearance (PHC). 
c. PT. Pelindo III Cabang Tanjung Emas Semarang.

PT Pelabuhan Indonesia III atau disingkat Pelindo III adalah Badan Usaha Milik Negara (BUMN) yang bergerak di bidang Jasa Kepelabuhanan. PT Pelindo III (Persero) yang menjalankan bisnis inti sebagai penyedia fasilitas jasa kepelabuhanan, memiliki peran kunci untuk menjamin kelangsungan dan kelancaran angkutan laut. Berdasarkan UU No. 17 Tahun 2008 tentang Penyelenggaraan Pelabuhan Umum, PT Pelindo III (Persero) bertanggung jawab atas Keselamatan Pelayaran, Penyelenggaraan Pelabuhan, Angkutan Perairan dan Lingkungan Maritim. Dalam kaitannya dengan kedatangan sebuah kapal, baik itu kapal asing ataupun kapal lokal, PT. PELINDO III telah meluncurukan suatu sistem yang dinamakan IBS PELINDO (Integrated Billing System). Sistem ini dirasa cukup efisien dan sangat bermanfaat bagi pengguna jasa kepelabuhanan. Hanya dengan smartphone ataupun komputer, sistem IBS PELINDO dapat diakses dengan mudah. Para pengguna jasa kepelabuhanan Pelindo III tidak perlu lagi datang ke kantor Pelindo III untuk mengajukan permohonan sandar kapal. Cukup dengan menggunakan aplikasi Integrated Billing System atau IBS, dengan masuk ke website anjungan.pelindo.co.id, para pengguna jasa kepelabuhanan sudah dapat mengajukan permohonan sandar kapal. Aplikasi IBS tersebut merupakan sebuah platform sistem informasi pelayanan jasa pelabuhan berbasis online yang mudah di akses oleh pengguna jasa kepelabuhanan dimanapun dan kapanpun.

Enam pilar yang menjadi unggulan pelayanan berbasis teknologi informasi IBS, yakni E-Regristration, E-Booking, EPayment, E-Billing, E-Care dan E-Tracking. Beberapa manfaat dari penerapan sistem IBS antara lain transparansi biaya, efisien penggunaan kertas, kemudahan tracking dalam permohonan serta pelayanan. Selain itu penggunaan IBS ini juga sejalan dengan tujuan Pelindo III untuk menjadikan seluruh Pelabuhan yang di kelolanya menjadi Eco Green Port, 
karena dengan penggunaan sistem tersebut dinilai dapat mengurangi konsumsi kertas.

\section{d. Perusahaan Bongkar Muat (PBM)}

Perusahaan Bongkar Muat (PBM) adalah Perusahaan yang berbadan hukum yang melakukan kegiatan bongkar muat barang dari dan atau ke kapal meliputi kegiatan pembongkaran barang dari palka kapal ke atas dermaga di lambung kapal atau sebaliknya (stevedoring), kegiatan pemindahan barang dari dermaga di lambung kapal ke gudang/lapangan penumpukan atau sebaliknya (cargodoring) dan kegiatan pengambilan barang dari gudang/ lapangan di bawa ke atas truck atau sebaliknya (receiving/delivery)

\section{e. Divisi Kepanduan dan Pilot Station}

Pelayanan jasa pandu terdiri atas pemanduan kapal dan penundaan (penarikan) kapal dengan jasa kapal tug-boat. Pelayanan ini disediakan dengan alasan keselamatan kapal guna memberi arah gerak kapal yang aman memasuki atau keluar alur navigasi pelabuhan. Jasa ini wajib dipakai kapal karena alasan konvensi internasional walaupun kapal telah terbiasa memasuki wilayah perairan tersebut. Berkaitan dengan pelayanan kedatangan kapal, sejak tahun 2017 telah ada sistem yang diluncurkan oleh PT. PELINDO I-IV, bahwasanya untuk memudahkan dalam pelayanan baik jasa pandu, tambat. tunda, dan labuh serta pelayanan lainnya maka sistem IBS (Integrated Billing System) diluncurkan. Dengan sistem ini segala pelayanan jadi lebih mudah, cepat serta efisien dan tidak memerlukan waktu lama untuk booking layanan ini. Sehingga kedatangan sebuah kapal dapat cepat terlaksana dengan aman karena adanya sistem ini.

\section{f. Keimigrasian}

Keimigrasian Indonesia diatur dalam Undang-Undang No. 6 tahun 2011 tentang Keimigrasian. Menurut Pasal 1 angka 1 UU Keimigrasian, Keimigrasian adalah hal ihwal lalu lintas orang yang masuk atau keluar Wilayah Indonesia serta pengawasannya dalam rangka menjaga tegaknya kedaulatan 
negara. Keimigrasian merupakan bagian dari perwujudan pelaksanaan penegakan kedaulatan atas Wilayah Indonesia dalam rangka menjaga ketertiban kehidupan berbangsa dan bernegara menuju masyarakat yang adil dan makmur berdasarkan Pancasila dan Undang-Undang Dasar Negara Republik Indonesia Tahun 1945. Fungsi Keimigrasian adalah bagian dari urusan pemerintahan negara dalam memberikan pelayanan Keimigrasian, penegakan hukum, keamanan negara, fasilitator pembangunan kesejahteraan masyarakat.. Ketika dokumen dari kapal telah dibawa oleh pihak keagenan, maka pihak keagenan akan menyerahkan beberapa dokumen yang harus diperiksa oleh keimigrasian.

Prosedur ini dilakukan sesuai dengan UU Nomor 44 Tahun 2015 Tentang Tata Cara Pemeriksaan Masuk Dan Keluar Wilayah Indonesia Di Tempat Pemeriksaan Imigrasi.

\section{g. Kepabeanan dan Cukai}

Lembaga Bea cukai ini bukan sebuah istilah yang memiliki satu pengertian, melainkan dua istilah yang juga memiliki pengertian yang berbeda. Bea sendiri merupakan suatu tindakan pungutuan dari pemerintah terhadap barang ekspor atau impor, sedangkan cukai adalah pungutan negara kepada suatu barang yang memiliki sifat atau karakteristik yang sudah ditetapkan dalam Undang-Undang Cukai. Berkaitan dengan kedatangan sebuah kapal terutama kapal asing, maka pemeriksaan seperti ini sangat perlu dilakukan pemeriksaan untuk memastikan tidak terdapat barang- barang larangan pembatasan yang memerlukan ijin dari instansi terkait.

PT. Kharisma Indah Lestari sebagai agen menyerahkan surat pengantar dalam bentuk inward manifest. Kemudian instansi bea dan cukai akan memberikan surat penerimaan manifest yang ditanda tangani oleh penjabat instansi setempat.

Batas waktu dalam penyerahan inward manifest adalah 1x24 jam setelah kapal tiba dipelabuhan. 
3. Dokumen kapal yang dibutuhkan dalam proses kedatangan kapal di PT. Kharisma Indah Lestari Shipping Tanjung Emas Semarang

Berdasarkan peraturan menteri perhubungan Nomor PM 23 Tahun 2014 suatu kapal dalam melaksanakan suatu kegiatan clearance in harus didasari dengan dokumen-dokumen yang menguatkan fungsi dari masing-masing untuk memenuhi persyaratan kapal laut dan administrasi. Dokumen- dokumen tersebut dibagi menjadi dua bagian yaitu:

\section{a. Ship's Document}

Ship's Document atau disebut dokumen kapal yaitu dokumen yang harus dimiliki oleh setiap kapal dan harus berada di atas kapal, yang menyatakan tentang kelayak lautan kapal dalam berbagai fungsi atau bidang tertentu Ship's Document yang diambil dari atas kapal oleh perusahaan pelayaran. Ship's Document dibagi menjadi dua yaitu Returnable Ship Document dan Non Returnable Ship Document.

\section{b. Dokumen Muatan}

Tidak hanya Ship Document saja yang berada diatas kapal, agen pelayaran juga berhak membuat dokumen barang-barang yang dimuat keatas kapal yang disebut dokumen muatan.

Dokumen untuk muatan diantaranya adalah :

Bill of Lading, Cargo Manifest, Notice of Readiness (NOR), Statement of Fact,

Mate's Receipt,

Dokumen-dokumen seperti ini apabila kapal asing, akan dikirimkan melalui e-mail dengan judul pre-arrival docs. Walaupun begitu, tetap saja terkadang ada dokumen kapal yang kurang ataupun expired jadi pihak keagenan harus benarbenar mengecek dokumen kapal apakah sudah lengkap atau belum. 


\section{E. KESIMPULAN}

1. Gangguan server pada sistem INAPORTNET dan IBS PELINDO akan tetap terjadi apabila tidak ada perubahan dari server utama yang dipegang oleh Dirjen Hubla dan PT. Pelindo. Jika terjadi gangguan server secara terus menerus maka akan berakibat fatal dan mau tidak mau harus menggunakan clearance manual.

2. Koordinasi antara instansi-instansi seperti karantina kesehatan, perusahaan bongkar muat, imigrasi, dan instansi lainnya sangat perlu diperhatikan agar pelayanan kedatangan kapal berjalan dengan lancar.

3. Dalam pelayanan kedatangan sebuah kapal tedapat 2 dokumen yaitu Ship's Document atau dokumen kapal dan dokumen muatan, yang disampaikan ke agen dikirim melalui e-mail terlebih dahulu dengan judul pre-arrival docs.

\section{F. DAFATAR PUSTAKA}

Abbas Salim, H. A. 2013. Manajemen Transportasi. edisi ke11. Jakarta: PT. Raja Grafindo Persada.

DS, Hardjono. 2018. Peraturan Pencegahan Tubrukan Di Laut (P2TL). edisi ke-1 Semarang: CV. Patriangga.

Fakhrurrozi. 2016. Penanganan, Pengatturan, dan Pengamanan Muatan Kapal, Sleman: Deepublish CV. Budi Utama.

Widiyanti, Elok dan Ridwan. 2014. Kamus Kepelabuhanan dan Pelayaran. Yogyakarta: Leutikaprio.

Keputusan Menteri Perhubungan No.KM.33 Tahun 2001 Tentang Penyelenggaraan Dan Pengusahaan Angkatan Laut. Jakarta: Menteri Perhubungan.

Republik Indonesia. Undang-Undang Nomor 17 Tahun 2008 Tentang Pelayaran Pasal 1 Ayat 7 dan 36. Lembaran Negara RI Tahun 2008, No. 64. Jakarta: Menkumham. 
Hamid. 2017. Permohonan Sandar Kapal di Pelindo III, Menggunakan Aplikasi IBS. [Online]. 